\title{
Hard-soft thiol-ene materials without interfacial weakness
}

Shen, Peng; Moghaddam, Saeed Zajforoushan; Huang, Qian; Daugaard, Anders Egede; Zhang, Suojiang; Szabo, Peter

Published in:

Materials Today Communications

Link to article, DOI:

10.1016/j.mtcomm.2019.100657

Publication date:

2019

Document Version

Peer reviewed version

Link back to DTU Orbit

Citation $(A P A)$ :

Shen, P., Moghaddam, S. Z., Huang, Q., Daugaard, A. E., Zhang, S., \& Szabo, P. (2019). Hard-soft thiol-ene materials without interfacial weakness. Materials Today Communications, 21, [100657].

https://doi.org/10.1016/j.mtcomm.2019.100657

\section{General rights}

Copyright and moral rights for the publications made accessible in the public portal are retained by the authors and/or other copyright owners and it is a condition of accessing publications that users recognise and abide by the legal requirements associated with these rights.

- Users may download and print one copy of any publication from the public portal for the purpose of private study or research.

- You may not further distribute the material or use it for any profit-making activity or commercial gain

- You may freely distribute the URL identifying the publication in the public portal

If you believe that this document breaches copyright please contact us providing details, and we will remove access to the work immediately and investigate your claim. 


\title{
Hard-soft Thiol-ene Materials without Interfacial Weakness
}

\author{
Peng Shen, ${ }^{1}$ Saeed Zajforoushan Moghaddam, ${ }^{2}$ Qian Huang, ${ }^{1}$ Anders Egede \\ Daugaard, ${ }^{1}$ Suojiang Zhang, ${ }^{3^{*}}$ Peter Szabo ${ }^{{ }^{*}}$
}

\begin{abstract}
${ }^{1}$ Department of Chemical and Biochemical Engineering, Danish Polymer Centre, Technical University of Denmark (DTU), Søltofts Plads, Building 229, DK - 2800 Kgs, Lyngby, Denmark

2Department of Chemistry, Technical University of Denmark (DTU), Kemitorvet, Building 206, DK 2800 Kgs, Lyngby, Denmark

${ }^{3}$ Beijing Key Laboratory of lonic Liquids Clean Process, Key Laboratory of Green Process and Engineering, Institute of Process Engineering, Chinese Academy of Sciences, Beijing 100190, PR China
\end{abstract}

Correspondence to: Peter Szabo (E-mail: ps@kt.dtu.dk), Suojiang Zhang (E-mail: sjzhang@ipe.ac.cn)

\begin{abstract}
Thiol-ene materials are a series of materials that can be crosslinked using a suitable photo-initiator and a UV light source. An advantage of thiol-ene materials is that they can be tailored to have specific mechanical properties by controlling the stoichiometry of the mixtures. By combination of different reactants, it is therefore, in principle, possible to prepare monoliths with greatly varying mechanical properties from essentially the same material. In this paper, we prepared an alternating hard and soft thiol-ene material with a sharp solid interface. Tetrakis (3mercaptopropionate) (PETMP) with 1, 3, 5-triallyl-1, 3, 5-triazine-2, 4, 6(1H, 3H, $5 \mathrm{H}$ )-trione (TATATO) as the hard segment exhibited strong tensile and compressive strength but had low elongation and weak bending stiffness. A mixture of PETMP and trimethylolpropane diallyl ether (TMPDE) was selected as the soft segment. After stretching at $0.001 \mathrm{~s}^{-1}$ using a filament stretching rheometer (FSR), the soft segment fractured at the strain of $21 \%$, while the interface of the materials was strong enough to prevent cracking.
\end{abstract}

KEYWORDS: thiol-ene materials, solid interface, filament stretching rheometer

\section{INTRODUCTION}

The layer-by-layer (LBL) technique has received significant scientific and technological interest as an effective and powerful approach to prepare materials with specific properties[1-3]. It has been widely used in biomedical materials[4], ecomaterials[5], and energy materials[6], to mention a few. Polymer materials with a LBL structure are usually composed of two polymers with different physical and chemical properties. The combined system takes advantage of both components, which results in improved performance, and thus extends the application area compared to the respective homopolymers.

The interface between the two polymers in LBL systems, as the junction surface, plays an essential role for the overall mechanical performance of such systems. In particular, the mechanical properties of the interface are crucial to the usability[7]. Insufficient interfacial adhesion between the two polymers leads to fracture during elongation or impact; such materials often exhibit initial fracture at the interface or near the interface. Typically, such interfaces can be reinforced by use of copolymers 
to increase the bond strength between the two polymer phases. A.R. Kamdar et al.[8] examined the effect of chain microstructure on the adhesion of the interface of a PP/HDPE blend, which was compatibilized with a copolymer. They observed that all the failures occurred at the PP-copolymer interface, indicating that the copolymer exhibited better adhesion to HDPE than to PP, though the interfacial strength was improved by addition of the copolymer. T. Ebeling et al.[9] used $0.5 \%$ maleic anhydride as a compatibilizer in the tie layer to increase the interfacial toughness. After peel tests, they found that the crack tip reduced the stress concentration at the interface and increased the toughness, but the tie layer began to crack when the materials were subjected to a tensile load. The poor mechanical properties were caused by an unstable phase morphology and poor interfacial adhesion. Another procedure applied is to reinforce interfaces to increase the temperature above the glass transition temperature or melting point after the LBL materials were prepared, so that the interface of the two materials fuse together. Yang et al.[10] employed this method and contacted two similar pieces of bulk polymers at a temperature above the glass transition, but the chain diffusion across the interface was insufficient, and the strength of the interface was not strong enough. In order to solve this problem, we designed a chemical method of step-by-step pre-crosslinking to prepare new hard-soft alternate thiol-ene material, which had a similar structure as LBL polymer systems, but results in a significantly stronger interphase.

Thiol-ene materials can be obtained through thermal crosslinking with common azoinitiators such as 2,2-azobis(isobutyronitrile) (AIBN) or with little or no added photoinitiators through photochemical thiol-ene[11-15]. During the last century, thiol-ene materials have received significant attention because of the highly efficient reactions of thiols with reactive $\mathrm{C}=\mathrm{C}$ bonds in allyl or acrylate systems. Thiol-ene materials have been applied in hydrogels, coatings, adhesives, particles, optical applications, dendrimer synthesis, all-solid-state electrolyte, high strength laminates, dental resins and electroluminescent films[11,16-19]. There are two typical thiol reactions, including thiol-ene free-radical addition to electron-rich/electron-poor $\mathrm{C}=\mathrm{C}$ bonds, and the catalyzed thiol Michael addition to electron-deficient $\mathrm{C}=\mathrm{C}$ bonds[20,21]. Unlike typical chain-growth free-radical polymerizations, thiol-ene polymers form in a stepwise manner [22,23], through a rapid and highly efficient free-radical chaintransfer reaction. Thus, crosslinked thiol-ene polymerizations proceed very rapidly but due to the step-growth characteristics of polymerization would not reach the gelpoint until relatively high functional group conversions, resulting in a material with very low shrinkage and low inherent stresses[24,25].

LBL alternating materials have a unique structure, which contains both hardness of solid materials and toughness of soft materials. Aziz et al.[7] have used a photoclickable poly (ethylene glycol) hydrogel to form bilayer hydrogels by sequential cross linking addition of new pristine reagents and final cross linking of the second layer. They studied the relation of soaking time and hydrogel crosslinking density on the LBL structure. By controlling the processing conditions, the thickness of the interface can be tuned without affecting the mechanical properties of the bulk hydrogel. Huang et al.[26] demonstrated a facile and scalable method to fabricate spine-like Li-ion batteries with remarkable flexibility, mechanical stability, and electrochemical performance. The hard part was used for storing energy while the soft part provided excellent flexibility for the battery. Based on this hard-soft alternating 
structure, the maximum strain $(\approx 0.08 \%)$ was markedly reduced compared to traditional stacked cells $(\approx 1.1 \%)$. Thus, the hard-soft materials have great potential in applications of multitudinous mechanical properties for engineering constructions. The interfacial strength of hard and soft segments was the pivotal factor for the mechanical properties of such alternating materials, requiring that the interface should be rigid and of sufficient strength to prevent cracking during the deformation. In this paper, we prepared new monolithic thiol-ene materials containing both a soft and hard segment with a seamless integration of the two phases.

\section{EXPERIMENTAL METHODS}

\section{Materials}

Sylgard 184 elastomer kit used for the Poly (dimethyl siloxane) (PDMS) mold was purchased from Dow Corning. Ethyl (2, 4, 6-trimethylbenzoyl) phenyl phosphinate (TPO-L) used as UV initiator was supplied from BASF. The Chemical structures of Tetrakis (3-mercaptopropionate) (PETMP) (Figure 1a), 1, 3, 5-Triallyl-1, 3, 5triazine-2, 4, 6(1H, 3H, 5H)-trione (TATATO) (Figure 1b), and trime-thylolpropane diallyl ether (TMPDE) (Figure 1c) were obtained from Tokyo Chemical Industry Co., Ltd.<smiles></smiles>

$\mathbf{a}$<smiles>C=CCC1C(=O)C(CC=C)C(=O)C(CC=C)C1=O</smiles><smiles>C=CCOCC(CC)(CO)COCC=C</smiles>

Figure 1. Chemical structure of (a) tetrakis(3-mercaptopropionate), (b) 1,3,5-triallyl-1,3,5triazine-2,4,6 $(1 \mathrm{H}, 3 \mathrm{H}, 5 \mathrm{H})$-trione and $(\mathbf{c})$ trimethylolpropane diallyl ether

\section{Mold preparation}

PDMS is a vinyl terminated liquid silicone rubber and it can be solidified as a crosslinked elastomer at room temperature. PDMS molds were prepared by using the ratio (10:1, wt.) of elastomer to curing agent. After these two materials were mixed in a SpeedMixer at a speed of 3000r/min for $3 \mathrm{mins}$, the homogenous liquid mixture was poured into a flat-bottomed glass test tube $(\varnothing=1 \mathrm{~cm}, \mathrm{H}=7 \mathrm{~cm})$, and a glass rod $(\varnothing=0.5 \mathrm{~cm}, \mathrm{H}=10 \mathrm{~cm})$ was inserted into the tube. For fixing the rod in the center of the tube, we used a small plastic plate with a hole $(\varnothing=0.5 \mathrm{~cm})$. The tube with the PDMS liquid was kept at room temperature for $2 \mathrm{~h}$ to remove the air bubbles; the mold was cured for $24 \mathrm{~h}$ at $80^{\circ} \mathrm{C}$ in an oven. The hollow cylinder PDMS mold was obtained by removing the tube and rod. 


\section{Step-by-step sample preparation}

\section{Preparation of rods with hard-soft interface}

For preparing the column shaped sample with sandwich structure, we made the hard and soft segment polymer, respectively. The hard segment polymer liquid was prepared by using the ratio $(1: 1)$ of PETMP to TATATO. The two chemicals were mixed in a SpeedMixer at the speed of 3000r/min for $2 \mathrm{mins}$; in addition, all processes should be completed in total darkness for preventing the mixture from premature polymerization. The soft liquid was obtained in the same way except for replacing the TATATO with TMPDE.

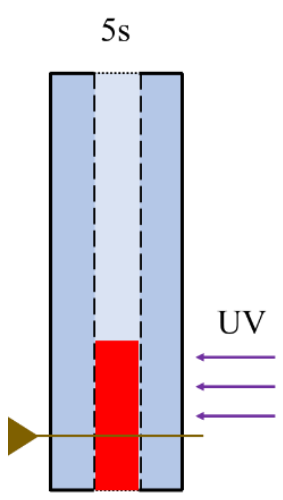

a

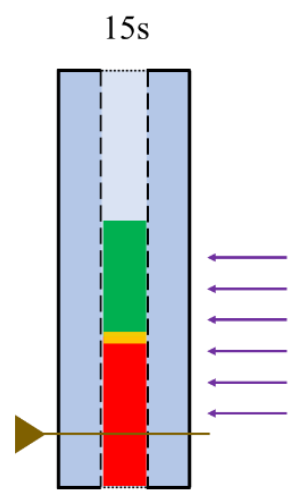

b

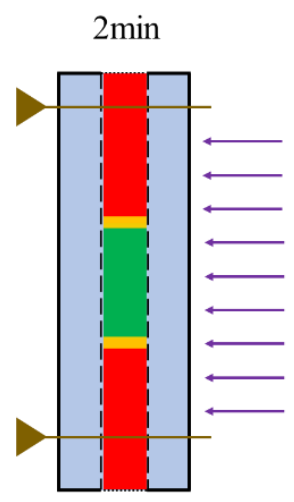

c

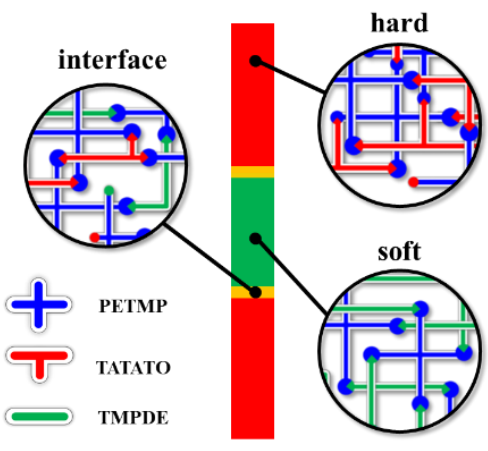

d

Figure 2. The production process (a-c.) for a $10 \mathrm{~mm}$ soft segment hard-soft alternate sample, The structure of soft-hard alternate material (d).

A syringe needle was impaled into the bottom of the mold through the diameter (Figure 2a), and then the hard segment polymer liquid was slowly poured into the mold by using a $10 \mathrm{~mL}$ syringe. The mold was placed in a vacuum drying oven to remove air bubbles at room temperature, when the liquid level raised to $1 \mathrm{~cm}$ (base of the needle). After that, the mold was exposed by ultraviolet light $\left(5-10 \mathrm{~mW} / \mathrm{cm}^{2}, \lambda\right.$ $=365 \mathrm{~nm}$ ) for 5 seconds (Figure $2 \mathbf{b}$ ). Then $1 \mathrm{~cm}$ soft liquid and $1 \mathrm{~cm}$ hard liquid were injected into the mold in turn by the same procedure.

The soft segment polymer has a lower polymerization rate, so the exposure time was increased to 15 seconds. After that, the remaining hard segment polymer liquid was added to the mold in the same way. The mold was placed in the UV-light ( $\lambda$ $=365 \mathrm{~nm}$ ) box for 2 mins to complete the process. A cylindrical hard-soft-hard alternate sample could be obtained after removing the needles and demolding.

\section{Linear viscoelastic (LVE) properties}

The linear viscoelastic properties of the soft segment material (PETMP/TMPDE) were obtained by small amplitude oscillatory shear flow measurements. An $8 \mathrm{~mm}$ plate-plate geometry was used on an ARES-G2 rheometer from TA instruments. The measurements for the material were performed at $25^{\circ} \mathrm{C}$.

\section{Differential scanning calorimetry (DSC) analysis}

DSC analysis was conducted by a Discovery series from TA Instruments to analyze the thermal properties of the hard polymer segment and soft polymer segment, respectively. Each kind of specimen was placed in an aluminum pan with the weight 
of $5 \mathrm{mg}$ for the DSC analysis. The DSC scan was carried out with heating rate of $10^{\circ} \mathrm{C} / \mathrm{min}$ from $-80{ }^{\circ} \mathrm{C}$ to $150{ }^{\circ} \mathrm{C}$ under nitrogen atmosphere $(50 \mathrm{~mL} / \mathrm{min})$.

\section{Surface Characterization by atomic force microscope (AFM)}

The surface properties of hard segment, soft segment, and the interface were evaluated by AFM (Nano Wizard 3, JPK Instruments AG, Berlin, Germany). Quantitative Imaging (QI) mode was employed to obtain topographical, hardness, and adhesion images over the interface. A rectangular cantilever (HQ:CSC18/Al BS, MikroMasch) with normal spring constant of $0.03 \mathrm{~N} / \mathrm{m}$ and a conic probe of $8 \mathrm{~nm}$ radius was used. The sensitivity of the cantilever was calculated based on a measurement against bare silicon wafer surface, while the accurate spring constant was obtained using thermal noise method.[27] The surface modulus was measured by DMA model based on indentation test over 50 points on a $10 \times 10 \mu \mathrm{m} 2$ by using the conic tip of half-angle $20^{\circ}$ under $1.5 \pm 0.5 \mathrm{MPa}$. The surface modulus of the hard and soft segments were estimated by conducting force measurements on each area. A set point force of $50 \mathrm{nN}$ and relative velocity of $0.3 \mu \mathrm{m} / \mathrm{s}$ were used to collect 36 measurements over a $5 \times 5 \mu \mathrm{m}$ surface area (three replicas on new sampling areas were measured). A Hertzian model for the conic probe (half angle of $20^{\circ}$, Poisson's ration of 0.5) was used to estimate the surface elastic modulus. Before the test, the hard-soft material surface was cleaned with ethanol (99\%) and rinsed copiously with deionized water and then blown dry with nitrogen.

\section{Tensile and fracture experiments}

The rheological measurements were carried out using a filament stretching rheometer (VADER 1000 from Rheo Filament ApS) with a strain rate of $0.001 \mathrm{~s}^{-1}$ (See supporting information 2)[28-31]. Meanwhile, a high-speed camera (Photron Mini UX100 with a Navitar Zoom6000 lens) was used to capture the fracture process; and the captured optical images were used to measure the local strain of the deformed sample accurately during the crack propagation. A pair of stainless-steel fixtures were made as add-ons to the filament stretching rheometer. There were two small holes $(\varnothing=3 \mathrm{~mm})$ on the side of each fixture, which were used to keep the sample ends in the container during the stretching process. All experiments were performed at room temperature. (See supporting information 3).

\section{RESULTS AND DISCUSSION Thermal behavior}

DSC analysis was used to determine the thermal behavior of the pure hard and soft segment polymers, respectively. The DSC thermograms are shown in Figure 3, where each of these two samples show one glass transition temperature in the $-80^{\circ} \mathrm{C}-150^{\circ} \mathrm{C}$ range. The cross-linked polymers exhibit no melting point because of the high crosslinking degree. The glass transition temperature of the hard segment polymer was $55.7^{\circ} \mathrm{C}$, while the glass transition temperature of the soft segment was $-35.4^{\circ} \mathrm{C}$, sufficiently below room temperature to provide high flexibility. 


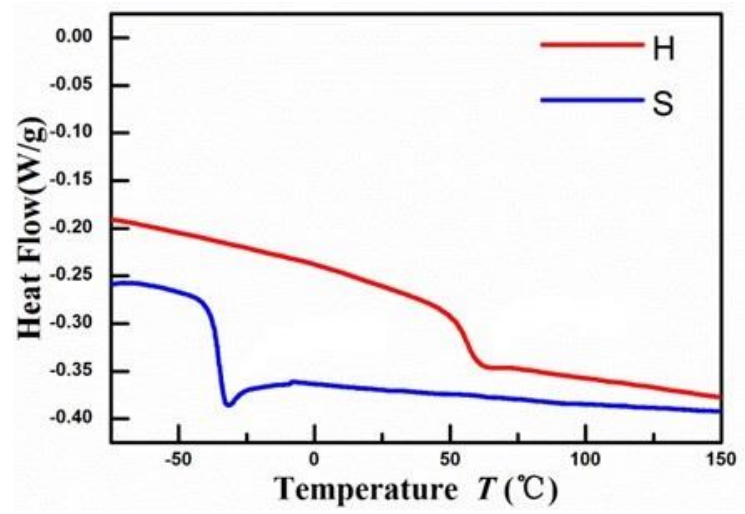

Figure 3. DSC curve of hard segment(H) and soft segment(S).

\section{Material structure}

The hard segment was prepared by photoinitiated thiol-ene cross-linking of PETMP/TATATO at a stoichiometric ratio of 1:1. The soft segment was prepared by PETMP/TMPDE using the same method. In both cases, it is possible to identify residual functional groups (vinyl and thiol) in the FT-IR spectra of the fully cured samples (supporting information). The photopolymerization rate of PETMP/ TATATO(3-arms vinyl) was almost six times faster than PETMP/ TMPDE(2-arms vinyl) under the identical curing conditions[23]. It was very important that the reaction time of the polymerization process in Figure $\mathbf{2 b}$ and $\mathbf{2 c}$ was strictly controlled (to ensure a sufficient chemical bonding at the interface). If the time was too long, the hard segment surface would become completely crosslinked and generate a weak interface, leading to interface cracking or separation during demolding. Oppositely, short exposure time would lead to a mix of the hard and soft liquids resulting in an undesired sample. The reaction time with 5 seconds for the hard segment and 15 seconds for the soft segment was a workable condition. As the hard segment and soft segment were not completely cured, the interface of the two polymers consists of PETMP/TATATO/ TMPDE (Figure 2d).

\section{Stress-strain responses during mechanical testing}

The VADER 1000 was used for measuring the stress-strain responses in the start-up of uniaxial elongational flow with a constant strain rate[32-34]. The volume of an idealized elastic material was conserved during deformation as shown in Figure 4a; therefore, we can conclude that $L_{0} D_{0}^{2}=L(t) D(t)^{2}$, where $L_{0}$ and $D_{0}$ were the initial length and diameter, and $L(t)$ and $D(t)$ were the detected length and diameter at time $t$. While the length of the alternate material was $L=2 L_{H}+L_{S}$ with diameter $D=D_{H 0}=D_{S O}$ (Figure 4b), the length and diameter of the hard segments were considered constant during the stretching[32,35-37], and the diameter variation of the soft segment, $D_{S}(t)$, was recorded by the laser micrometer in the VADER 1000. Due to the necking effect on the center of the soft segment, $D_{S O} \geqslant D_{S}(t)$. 

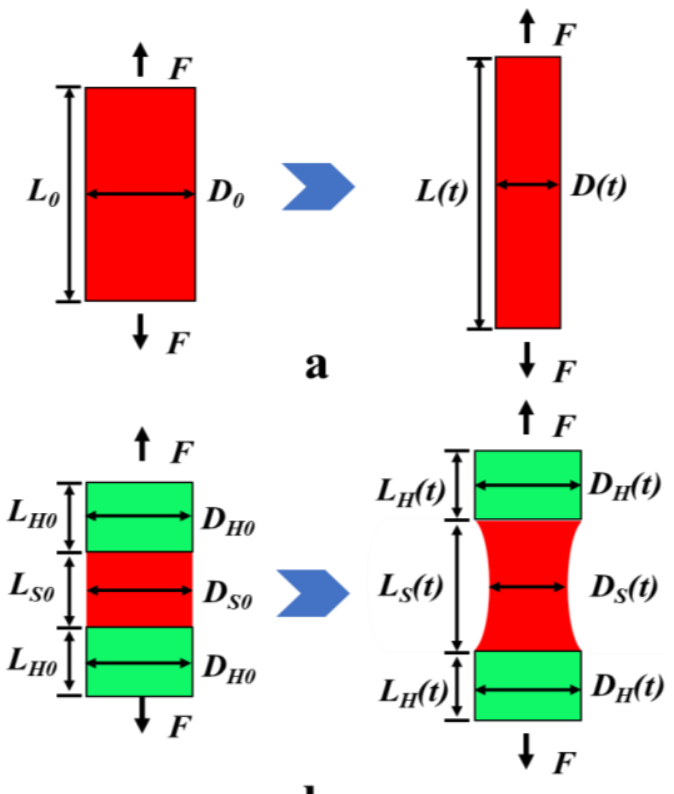

b

Figure 4. The stretch process of an idealized elastic (a) and hard-soft alternate sample (b)

Under the assumption of a constant sample volume during deformation, the true Hencky strain and the engineering strain could be used in this study. The true Hencky strain $\varepsilon_{h}$ and the engineering strain $\varepsilon_{e}$ were obtained from[38,39,40]:

$$
\varepsilon_{h}=2 \ln \frac{D_{0}}{D(t)} \quad, \quad \varepsilon_{e}=\frac{L(t)-L_{0}}{L_{0}}
$$

We defined the strain rate as $\dot{\varepsilon}=d \varepsilon_{h} / d t$. For the alternate material shown in Figure 4b, $L_{0}=2 L_{H 0}+L_{S O}, D_{0}=D_{S O}, L(t)=2 L_{H}(t)+L_{S}(t)$, and $D(t)=D_{S}(t)$. The true stress and engineering stress on the sample were defined as:

$$
\sigma_{h}=\frac{F}{A(t)}, \quad \sigma_{e}=\frac{F}{A_{0}}
$$

Here, $F$ is the tensile force recorded by the VADER $1000, A_{0}$ denotes the initial crosssectional area of the sample, and $A(t)$ is calculated from $D(t)$. Figure 5 shows the stress-strain curve for $\boldsymbol{\sigma}_{\boldsymbol{h}}, \boldsymbol{\varepsilon}_{\boldsymbol{h}}$ and $\boldsymbol{\sigma}_{\boldsymbol{e}}, \boldsymbol{\varepsilon}_{\boldsymbol{e}}$ respectively. As shown in Figure $\mathbf{6}$, the length of the sample increased linearly with time during stretching. The elongation of the sample was $21.0 \%$ and the reduction of the cross-sectional area was $34.4 \%$ before the crack appeared. 


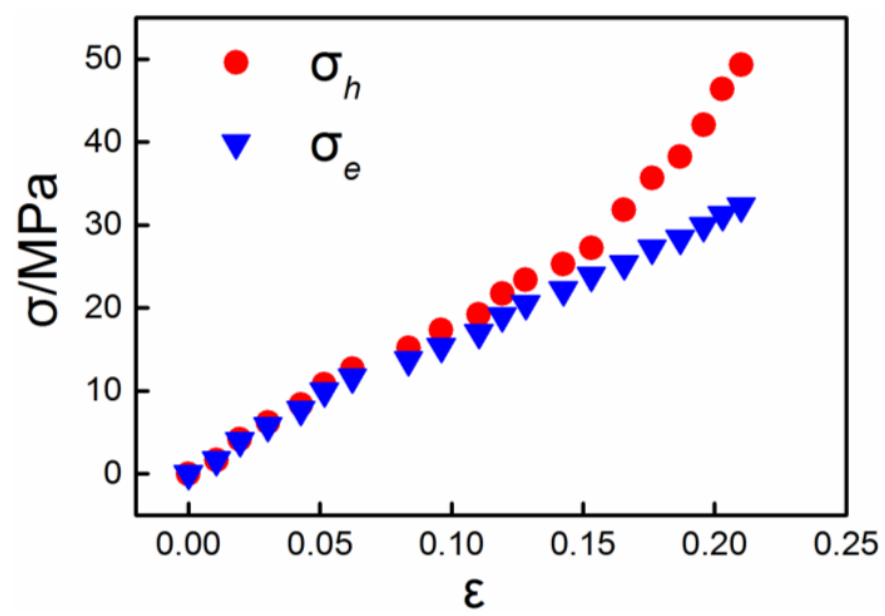

Figure 5. The curve for true Hencky strain-stress and the engineering strain-stress
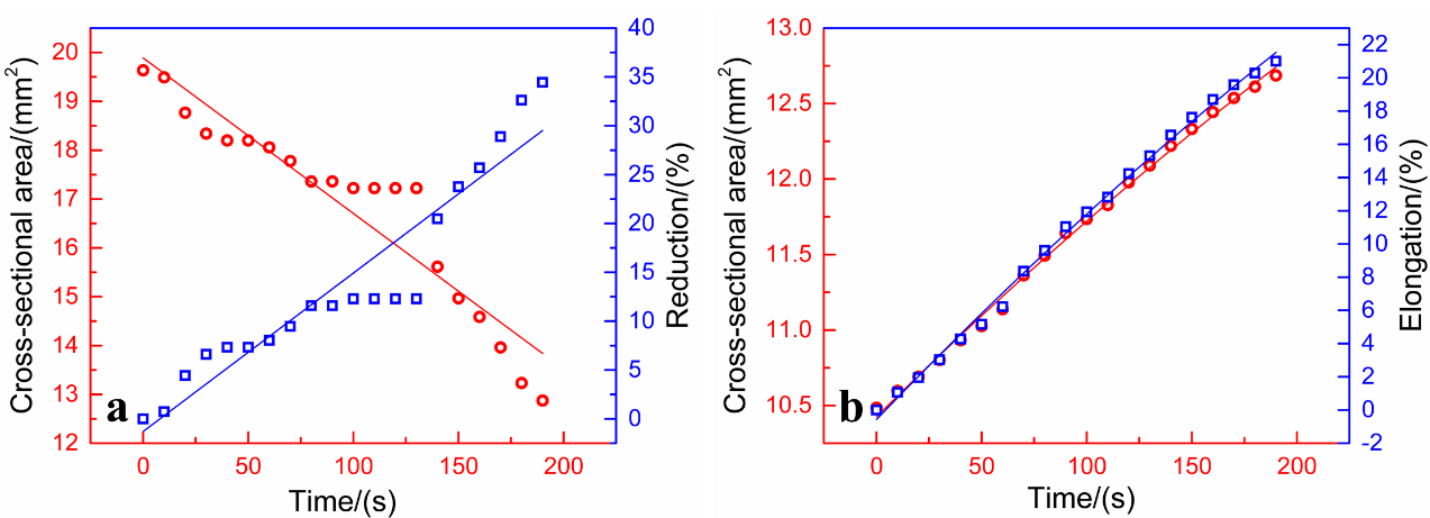

Figure 6. The curves for the reduction of cross-sectional area (a) and elongation of length (b)

\section{Fracture process}

The fracture process was too fast to be recorded by a conventional camera. We used the high-speed camera for recording the images of the fracture process[41-43]. As shown in Figure 7, the crack was generated in the soft segment surface, not in the interface between the hard and soft materials.

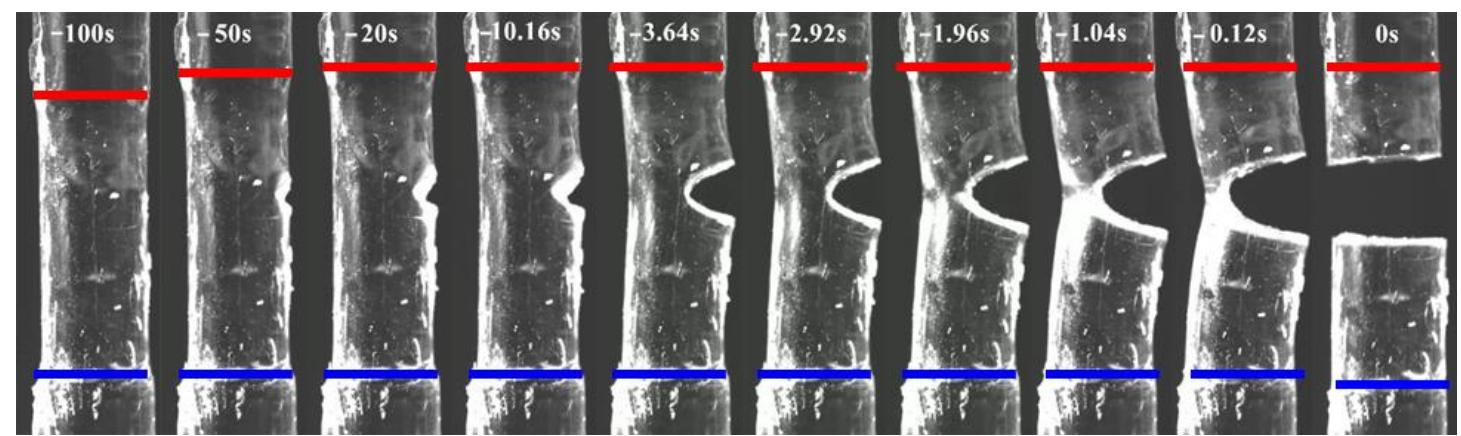

Figure 7. The image of $10 \mathrm{~mm}$ soft segment alternate materials fracture process (blue line shows the bottom interface, red the top)

The dynamic quantitative analysis of the fracture process is shown in Figure 8. The distance from the crack tip, represented in the $\mathrm{x}$-axis, was collected by image analysis using MATLAB[31,35,44-46]. We set $0 \mathrm{~s}$ as the time for complete fracture, and -95s as the fracture start time. The crack propagation can be divided into two stages: a slow stage from -95s to -15s (Figure 8b) and a fast stage from -10s to 0s (Figure 8a). 
The second fracture process could be fit using a parabola. The parabolic fit is shown by the black solid line. The overall fracture fitted the equation $u(x)=x^{0.5}$ (x represents distance from the fracture tip while $u(x)$ was the fracture opening). $[29,30,43,45,47]$ Associated with the frequency-dependent linear viscoelasticity (Figure 9), the storage modulus G' was bigger than loss modulus G', That explains why the crack profile showed typical parabola (for elastic fracture with little dissipation) when the crack propagates faster in Figure 8a.
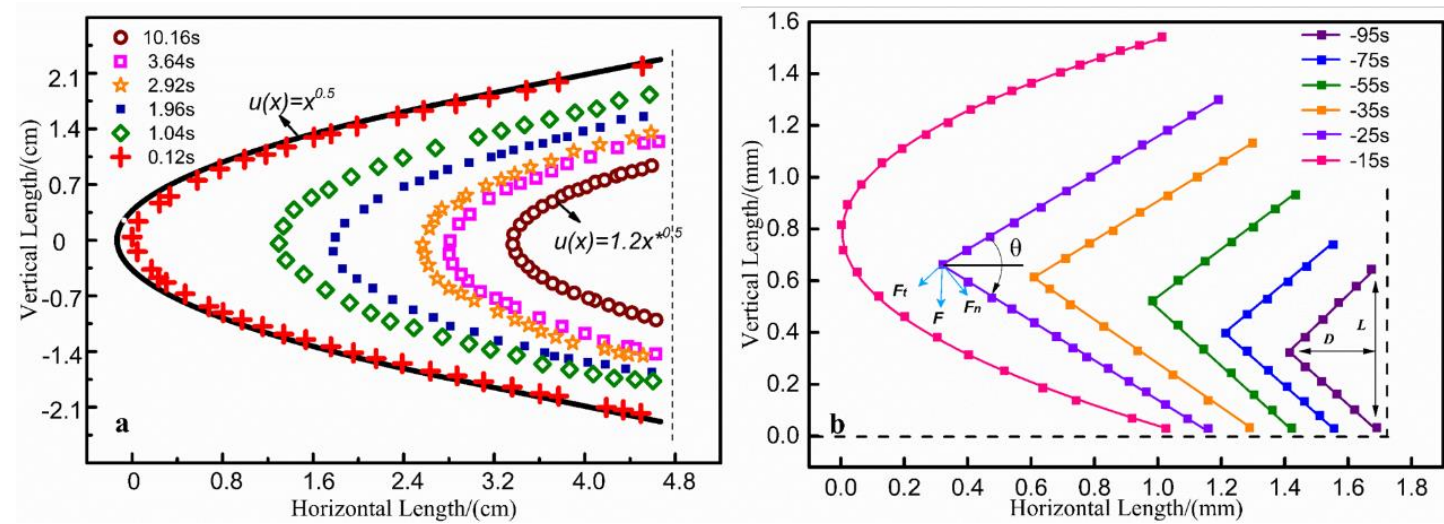

Figure 8. Fracture profile for entangled polymer soft segment alternate materials from (a) -

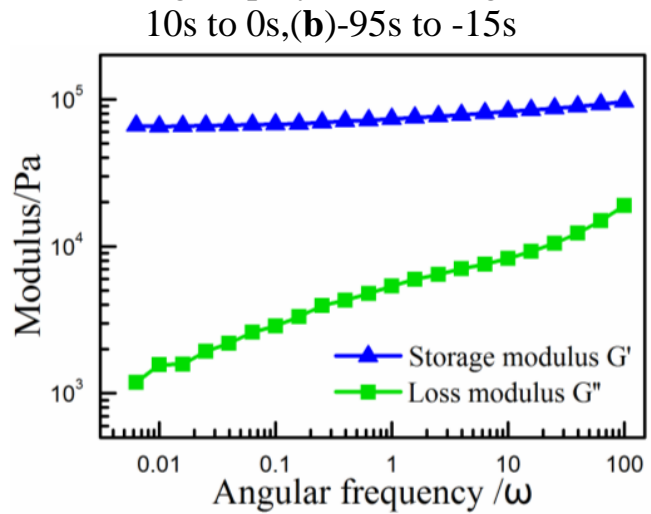

Figure 9. Frequency-dependent linear viscoelastic moduli for soft segment at $25^{\circ} \mathrm{C}$

We also changed the length of the soft segment from $10 \mathrm{~mm}$ to three different values (a. $1 \mathrm{~mm}$, b. $2.5 \mathrm{~mm}$ and c. $5 \mathrm{~mm}$ ) with the same diameter $(5 \mathrm{~mm})$. The aspect ratio of the soft segment is defined as $\Lambda_{s}=\mathrm{L}_{s 0} / \mathrm{D}_{0}$. Figure 10 shows the fracture process for the cases of $\Lambda_{S} \leq 1$, while the case of $\Lambda_{S}>1$ has already been shown in Figure 7. (1) When $\Lambda_{S}<1$, Figure 10 a and $\mathbf{b}$ show the fracture process for the soft segment with length $1 \mathrm{~mm}$ and $2.5 \mathrm{~mm}$, respectively. The necking effect was almost invisible, the feature was still a cohesive fracture in the soft segment. The crack did not take place in the soft segment interface. (2) When $\Lambda_{S}=1$, the material had a weak necking effect at the beginning of the stretch (Figure 10c), while again an oblique fracture was observed 


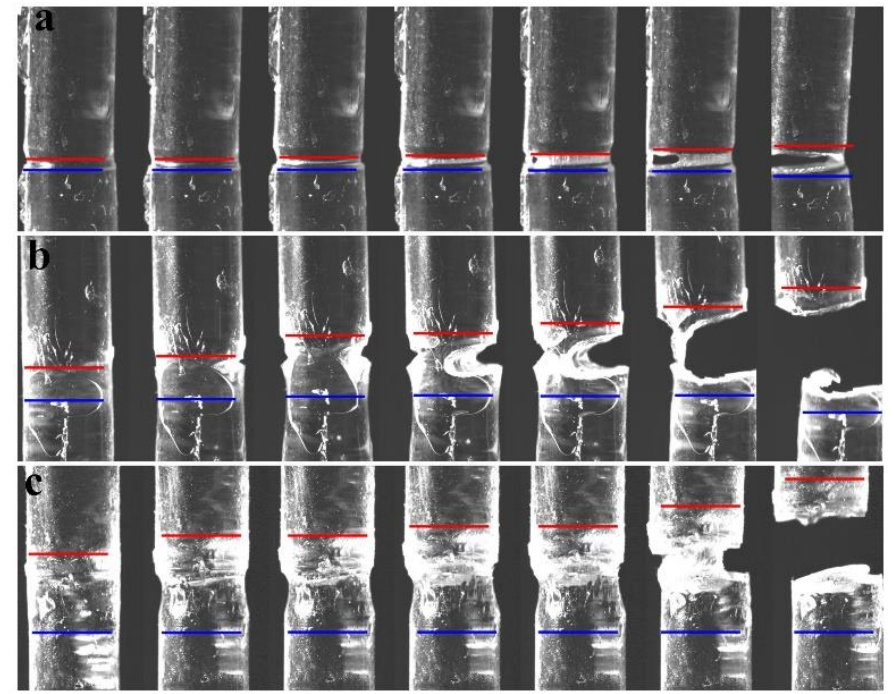

Figure 10. The image of $1 \mathrm{~mm}(\mathbf{a}), 2.5 \mathrm{~mm}(\mathbf{b})$ and $5 \mathrm{~mm}(\mathbf{c})$ soft segment alternate materials fracture process, (blue line shows the lower interface, red for upper interface).

\section{Interface enhancements}

Atomic force microscopy (AFM) images of hard-soft interface part are shown in Figure 11. The AFM cantilever scans the material surface from hard (left) to soft (right) across the interface. As shown in the height image of Figure 11b, the hard segment surface has the similar height with soft segment surface, but the interface is about $2 \mu \mathrm{m}$ higher than the plane of hard segment and soft segment because of swelling effect. The variation of modulus is shown in Figure 11c, the hard segment (orange) has significant contrast to the soft segment (black), suggesting a relatively larger surface modulus. The interface shows and intermediate modulus, which varies continuously versus the distance of the hard and soft segment. Similarly, Figure 11d indicates the change of adhesion across the interface.

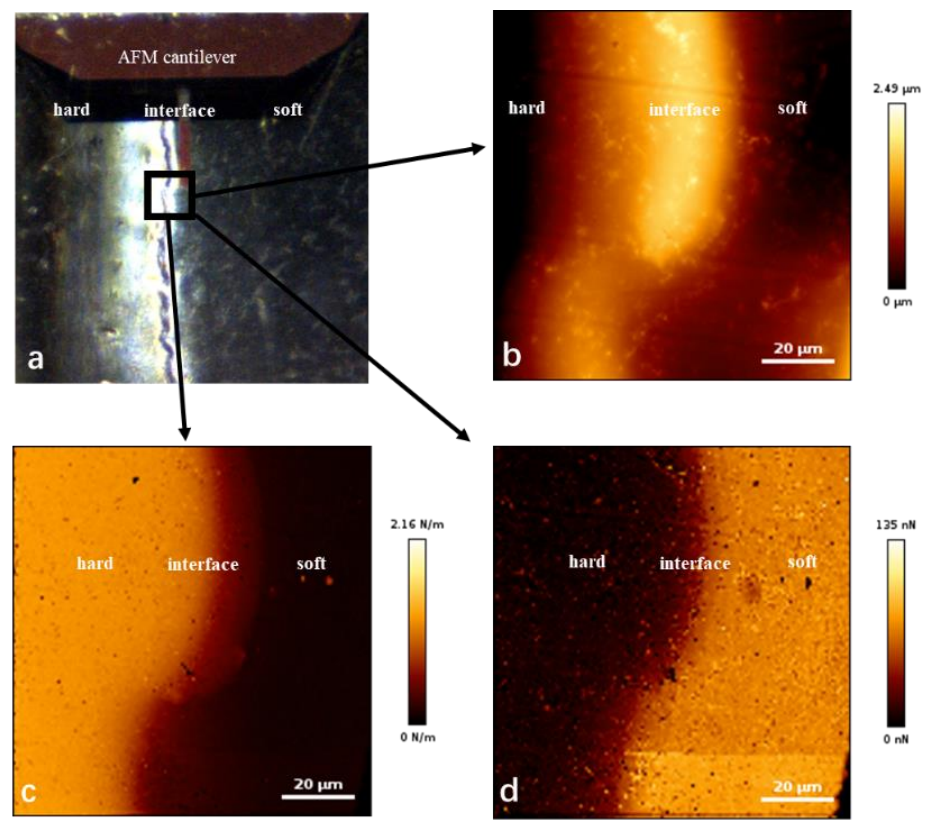

Figure 11 The junction surface of hard-soft material; (a) camera image, (b) height channel, (c) slope channel (measure of modulus), (d) adhesion channel. Obtained by Quantitative Imaging (QI) mode from the interface. 
Through the above-mentioned study, it is evident that the interface of the alternate materials with different sizes was strong enough to prevent premature fracture during stretching. By contrast, the interface of conventional LBL materials is narrow and connected by physical interactions, resulting in weak materials which easily fracture when stretched or bent.

There are two reasons for the step-by-step co-crosslinked method to improve the strength of interfaces:

1. Taking the first step as example, as shown in Figure 2, there were many thiol and vinyl groups, which were not crosslinked completely in the hard segment, due to the $2 \mathrm{D}$ geometry of the surface, these residual thiol and vinyl groups are free to react with new thiol groups and vinyl groups when the soft liquid is poured onto the surface. This results in formation of covalent bonds at the hard-soft interface, which have a significant impact on avoiding the interfacial fracture.

2. The reaction mixtures from the hard and soft segments were added before the surface was fully cured, which resulted in inter-diffusion of the boundary layer. In analogy, the hard segments can then be considered to hold the interface as a cement, while the soft segments increased the interface resilience as a steel rebar.

Based on the above two points, the interface had a structure similar to reinforced concrete, and had high mechanical performance supported by polymer chains of both hard and soft segments.

\section{CONCLUSIONS}

In summary, a new step-by-step pre-crosslinking method was designed to prepare hard-soft alternating thiol-ene materials. The overall mechanical properties of these materials are controlled by the interface between hard and soft segments. Compared to traditional LBL materials, the method significantly improved mechanical properties of the interface, hence, it can expand the application range of LBL materials considerably. The results provide a better understanding of how to improve the mechanical properties and a novel insight into rational design of controllable LBL materials. The alternate thiol-ene materials will be a new promising strategy to develop multifunctional material. The materials can also be utilized in other fields, such as artificial joints and flexible robots.

\section{ACKNOWLEDGEMENTS}

This work was supported by the Program for the China Scholarship Council Funding. Q.H. would like to acknowledge financial support from the Aage og Johanne LouisHansen Foundation. We would like to thank Dr.Liyun Yu (Danish Polymer Center, DTU) and Esben Thormann (Department of Chemistry, DTU) for help with DSC and AFM. 


\section{REFERENCES}

[1] C.D. Mueller, S. Nazarenko, T. Ebeling, T.L. Schuman, A. Hiltner, E. Baer, Novel structures by microlayer coextrusion - Talc-filled PP, PC/SAN, and HDPE/LLDPE, Polym Eng Sci. 37 (1997) 355-362. doi:10.1002/pen.11678.

[2] J. Duvall, C. Sellitti, C. Myers, A. Hiltner, E. Baer, Effect of Compatibilization on the Properties of Polypropylene/Polyamide-66 (75/25 Wt/Wt) Blends, J Appl Polym Sci. 52 (1994) 195-206. doi:10.1002/app.1994.070520207.

[3] J. Duvall, C. Sellitti, C. Myers, A. Hiltner, E. Baer, Interfacial effects produced by crystallization of polypropylene with polypropylene-g-maleic anhydride compatibilitzers, J Appl Polym Sci. 52 (1994) 207-216. doi:10.1002/app.1994.070520208.

[4] J.W. Chan, B. Yu, C.E. Hoyle, A.B. Lowe, The nucleophilic, phosphinecatalyzed thiol-ene click reaction and convergent star synthesis with RAFTprepared homopolymers, Polymer (Guildf). 50 (2009) 3158-3168. doi:10.1016/j.polymer.2009.04.030.

[5] C.E. Hoyle, A.B. Lowe, C.N. Bowman, Thiol-click chemistry: A multifaceted toolbox for small molecule and polymer synthesis, Chem Soc Rev. 39 (2010) 1355-1387. doi:10.1039/b901979k.

[6] M.J. Kade, D.J. Burke, C.J. Hawker, Sci., Part A: Polym. Chem. 2010, 48, 743-750, (n.d.).

[7] A.H. Aziz, J. Wahlquist, A. Sollner, V. Ferguson, F.W. Delrio, S.J. Bryant, Journal of the Mechanical Behavior of Biomedical Materials Mechanical characterization of sequentially layered photo-clickable thiol-ene hydrogels, 65 (2017) 454-465.

[8] A.R. Kamdar, R.K. Ayyer, B.C. Poon, G.R. Marchand, A. Hiltner, E. Baer, Effect of tie-layer thickness on the adhesion of ethylene-octene copolymers to polypropylene, Polymer (Guildf). 50 (2009) 3319-3328. doi:10.1016/j.polymer.2009.04.048.

[9] T. Ebeling, S. Norek, A. Hasan, A. Hiltner, E. Baer, Effect of a Tie Layer on the Delamination Toughness of Polypropylene and Polyamide-66 Microlayers, J Appl Polym Sci. 71 (1999) 1461-1467. doi:10.1002/(SICI)10974628(19990228)71:9<1461::AID-APP11>3.0.CO;2-0.

[10] F. Yang, R. Pitchumani, Healing of thermoplastic polymers at an interface under nonisothermal conditions, Macromolecules. 35 (2002) 3213-3224. doi:10.1021/ma010858o.

[11] A.B. Lowe, C.E. Hoyle, C.N. Bowman, Thiol-yne click chemistry: A powerful and versatile methodology for materials synthesis, J Mater Chem. 20 (2010) 4745-4750. doi:10.1039/b917102a.

[12] A.B. Lowe, Thiol-ene "click" reactions and recent applications in polymer and materials synthesis: A first update, Polym Chem. 5 (2014) 4820-4870. doi:10.1039/c4py00339j.

[13] C. Hoffmann, M.C. Stuparu, A. Daugaard, A. Khan, Aza-Michael addition reaction: Post-polymerization modification and preparation of PEI/PEG-based polyester hydrogels from enzymatically synthesized reactive polymers, $\mathrm{J}$ Polym Sci Part A Polym Chem. 53 (2015) 745-749. doi:10.1002/pola.27498.

[14] C. Hoffmann, V. Chiaula, L. Yu, M. Pinelo, J.M. Woodley, A.E. Daugaard, Simple Preparation of Thiol-Ene Particles in Glycerol and Surface Functionalization by Thiol-Ene Chemistry (TEC) and Surface Chain Transfer 
Free Radical Polymerization (SCT-FRP), Macromol Rapid Commun. 39 (2018) 1-6. doi:10.1002/marc.201700394.

[15] B.D. Fairbanks, E.A. Sims, K.S. Anseth, C.N. Bowman, Reaction rates and mechanisms for radical, photoinitated addition of thiols to alkynes, and implications for thiol-yne photopolymerizations and click reactions, Macromolecules. 43 (2010) 4113-4119. doi:10.1021/ma1002968.

[16] A.A. Aimetti, A.J. Machen, K.S. Anseth, Poly(ethylene glycol) hydrogels formed by thiol-ene photopolymerization for enzyme-responsive protein delivery, Biomaterials. 30 (2009) 6048-6054. doi:10.1016/j.biomaterials.2009.07.043.

[17] C.C. Lin, A. Raza, H. Shih, PEG hydrogels formed by thiol-ene photo-click chemistry and their effect on the formation and recovery of insulin-secreting cell spheroids, Biomaterials. 32 (2011) 9685-9695. doi:10.1016/j.biomaterials.2011.08.083.

[18] M. Black, J.W. Rawlins, Thiol-ene UV-curable coatings using vegetable oil macromonomers, Eur Polym J. 45 (2009) 1433-1441. doi:10.1016/j.eurpolymj.2009.02.007.

[19] Z. Chen, B.J. Chisholm, R. Patani, J.F. Wu, S. Fernando, K. Jogodzinski, D.C. Webster, Soy-based UV-curable thiol-ene coatings, J Coatings Technol Res. 7 (2010) 603-613. doi:10.1007/s11998-010-9241-x.

[20] B.D. Mather, K. Viswanathan, K.M. Miller, T.E. Long, Michael addition reactions in macromolecular design for emerging technologies, Prog Polym Sci. 31 (2006) 487-531. doi:10.1016/j.progpolymsci.2006.03.001.

[21] Z. Yang, Q. Chen, D. Zhou, Y. Bu, Synthesis of functional polymer materials via thiol-ene/yne click chemistry, Prog Chem. 24 (2012).

[22] B. Sen Chiou, R.J. English, S.A. Khan, Rheology and photo-cross-linking of thiol-ene polymers, Macromolecules. 29 (1996) 5368-5374. doi:10.1021/ma960383e.

[23] H. Lu, J.A. Carioscia, J.W. Stansbury, C.N. Bowman, Investigations of stepgrowth thiol-ene polymerizations for novel dental restoratives, Dent Mater. 21 (2005) 1129-1136. doi:10.1016/j.dental.2005.04.001.

[24] B.D. Fairbanks, M.P. Schwartz, A.E. Halevi, C.R. Nuttelman, C.N. Bowman, K.S. Anseth, A versatile synthetic extracellular matrix mimic via thiolnorbornene photopolymerization, Adv Mater. 21 (2009) 5005-5010. doi:10.1002/adma.200901808.

[25] E.M. Scanlan, V. Corcé, A. Malone, Synthetic applications of intramolecular thiol-ene "click" reactions, Molecules. 19 (2014) 19137-19151. doi:10.3390/molecules 191119137.

[26] Q. Huang, N.J. Alvarez, A. Shabbir, O. Hassager, Multiple Cracks Propagate Simultaneously in Polymer Liquids in Tension, Phys Rev Lett. 117 (2016) 1-5. doi:10.1103/PhysRevLett.117.087801.

[27] J.E. Sader, J.W.M. Chon, P. Mulvaney, Calibration of rectangular atomic force microscope cantilevers, Rev Sci Instrum. 70 (1999) 3967-3969. doi:10.1063/1.1150021.

[28] V. Tirtaatmadja, T. Sridhar, A filament stretching device for measurement of extensional viscosity, J Rheol (N Y N Y). 37 (1993) 1081-1102. doi:10.1122/1.550372.

[29] A. Bach, H.K. Rasmussen, O. Hassager, Extensional viscosity for polymer melts measured in the filament stretching rheometer, J Rheol (N Y N Y). 47 (2003) 429-441. doi:10.1122/1.1545072. 
[30] M.I. Kolte, H.K. Rasmussen, O. Hassager, Transient filament stretching rheometer II: Numerical simulation, Rheol Acta. 36 (1997) 285-302. doi: $10.1007 / \mathrm{s} 003970050047$.

[31] A.G. Bejenariu, H.K. Rasmussen, A.L. Skov, O. Hassager, S.M. Frankaer, Large amplitude oscillatory extension of soft polymeric networks, Rheol Acta. 49 (2010) 807-814. doi:10.1007/s00397-010-0464-7.

[32] R. Sizaire, V. Legat, Finite element simulation of a filament stretching extensional rheometer, J Nonnewton Fluid Mech. 71 (1997) 89-107. doi:10.1016/S0377-0257(97)00013-X.

[33] K.J. Ledeganck, C. Anné, A. De Monie, S. Meybosch, G.A. Verpooten, M. Vinckx, K. Van Hoeck, A. Van Eyck, B.Y. De Winter, D. Trouet, Longitudinal study of the role of epidermal growth factor on the fractional excretion of magnesium in children: Effect of calcineurin inhibitors, Nutrients. 10 (2018) 307-335. doi:10.3390/nu10060677.

[34] G.H. Mckinley, T. Sridhar, Filamaent-stretching rheometry of complex fluids, Annu Rev Fluid Mech. (2002) 375-415.

[35] P. Szabo, G.H. McKinley, C. Clasen, Constant force extensional rheometry of polymer solutions, J Nonnewton Fluid Mech. 169-170 (2012) 26-41. doi:10.1016/j.jnnfm.2011.11.003.

[36] P. Szabo, G.H. McKinley, Filament stretching rheometer: inertia compensation revisited, Rheol Acta. 42 (2003) 269-272. doi:10.1007/s00397-002-0277-4.

[37] G.H. Pearson, R.W. Connelly, The use of extensional rheometry to establish operating parameters for stretching processes, J Appl Polym Sci. 27 (1982) 969-981. doi:10.1002/app.1982.070270316.

[38] A.R. Jacob, A.P. Deshpande, L. Bouteiller, Large amplitude oscillatory shear of supramolecular materials, J Nonnewton Fluid Mech. 206 (2014) 40-56. doi:10.1016/j.jnnfm.2014.03.001.

[39] N.J. Alvarez, J.M.R. Marl'lin, Q. Huang, M.L. Michelsen, O. Hassager, Creep measurements confirm steady flow after stress maximum in extension of branched polymer melts, Phys Rev Lett. 110 (2013). doi:10.1103/PhysRevLett.110.168301.

[40] C.I. Fiedler, E.A. Aisenbrey, J.A. Wahlquist, C.M. Heveran, V.L. Ferguson, S.J. Bryant, R.R. McLeod, Enhanced mechanical properties of photo-clickable thiol-ene PEG hydrogels through repeated photopolymerization of in-swollen macromer, Soft Matter. 12 (2016) 9095-9104. doi:10.1039/c6sm01768a.

[41] Q. Huang, Molecular Rheology of Complex Fluids, 2013.

[42] Q. Huang, N.J. Alvarez, Y. Matsumiya, H.K. Rasmussen, H. Watanabe, O. Hassager, Extensional rheology of entangled polystyrene solutions suggests importance of nematic interactions, ACS Macro Lett. 2 (2013) 741-744. doi:10.1021/mz400319v.

[43] Q. Huang, H.K. Rasmussen, A.L. Skov, O. Hassager, Stress relaxation and reversed flow of low-density polyethylene melts following uniaxial extension, J Rheol (N Y N Y). 56 (2012) 1535-1554. doi:10.1122/1.4752759.

[44] Y. Zhou, C.M. Schroeder, Single polymer dynamics under large amplitude oscillatory extension, Phys Rev Fluids. 1 (2016) 53301. doi:10.1103/PhysRevFluids.1.053301.

[45] R.D. Egholm, S.F. Christensen, P. Szabo, Stress-strain behavior in uniaxial compression of polymer gel beads, J Appl Polym Sci. 102 (2006) 3037-3047. doi:10.1002/app.24715. 
[46] H.B. Kaushik, D.C. Rai, S.K. Jain, Stress-Strain Characteristics of Clay Brick Masonry under Uniaxial Compression, J Mater Civ Eng. 19 (2007) 728-739. doi:10.1061/(ASCE)0899-1561(2007)19:9(728).

[47] J.M. Román Marín, J.K. Huusom, N.J. Alvarez, Q. Huang, H.K. Rasmussen, A. Bach, A.L. Skov, O. Hassager, A control scheme for filament stretching rheometers with application to polymer melts, J Nonnewton Fluid Mech. 194 (2013) 14-22. doi:10.1016/j.jnnfm.2012.10.007. 